\title{
FIRST IMMUNOLOGICAL RECORD OF BABESIA MICROTI HOBET SULINEAGE ANTIBODIES AMONG HUMAN BLOOD DONORS IN QENA GOVERNORATE, UPPER EGYPT, EGYPT
}

\author{
By
}

OSAMA H. ABDELLAH ${ }^{1}$, NOHA SAMMER AHMED ${ }^{2}$, MOHAMMED H. HASSAN ${ }^{3}$ and ASMAA M. EL-KADY ${ }^{*}$

Department of Medical Parasitology ${ }^{1}$, Faculty of Medicine, South Valley University, P.O. Box 83523 Qena, Department of Medical Parasitology ${ }^{2}$, Faculty of Medicine, Sohag University, P.O. Box 82524 Sohag, and Department of Medical Biochemistry ${ }^{3}$, Faculty of Medicine, South Valley University, P.O. Box 83523 Qena, Egypt ( ${ }^{*}$ Correspondence: Asmaa.elkady@med.svu.edu.eg Tel.: +2011114229741) Abstract

The zoonotic babesiosis is a growing public health concern. This parasite mainly occurs in U.S. (B. microti) and Europe (B. divergens \& B. venatorum). Emerging cases have been increasingly reported worldwide especially in immunosuppressed individuals. Other than tick bite, possible modes of infection include perinatal transmission and blood transfusion. To date, in Egypt, three cases of human babesiosis were reported. This study evaluated Babesia spp. infection in man in Qena City. Forty three persons were examined. All sera were subjected to serological examination using either indirect fluorescent antibody test (IFA) or western blot (WB) analysis or both tests. Using IFA 13/43 patients were positive for Babesia at different titers. The five out of the 13 positive IFAT samples were positive by using WB test (11.6\%). This could be the first study in Qena that screened Egyptian patients using well-defined Babesia strain for human babesiosis. Blood transfusion is a possible babesiosis mode of infection to man and thus patients in need of blood transfusion may undergo immunosuppressive status so they may develop babesiosis, so screening of blood donors for human babesiosis is needed to exclude transfusion induced babesiosis.

Keywords: Egypt, Blood donors, Babesia microti, Hoetsu, Western Blot, IFA

\section{Introduction}

The human babesiosis, a zoonotic infection transmitted by Ixodid ticks, is an emerging public health problem worldwide. Babesia microti infection mainly occurred in the United States while $B$. divergens and $B$. venatorum were mainly in Europe. However, emerging cases caused by novel zoonotic Babesia spp. as well as parasites closely related to but well-known distinct from the pathogenic Babesia were increasingly reported worldwide (Ord and Lobo, 2015). The clinical manifestations of human babesiosis ranged from clinically asymptomatic infection to severe fulminant malaria-like illness, which led to death without proper treatment (Onyiche et al, 2019). It is clinically manifested when the carrier undergoes immunosuppression (Homer et al, 2000). Other than tick bite, possible modes of transmission include perinatal (Yabsley and Shock, 2012) and blood transfusion or needle-stick injury
(Abdel-Motagaly et al, 2017).

In Africa, human babesiosis has been rarely reported due to widespread of the risky malaria particularly the fatal malignant form (Saleh et al, 2019). But, babesiosis is an emerging tick borne zoonotic disease caused by intraerythrocytic parasites of the genus Babe sia. Babesiosis is one of the commonest infections of free-living animals worldwide and most prevalent in rodents, carnivores, sheep, and cattle, a fact increased the concern about the emerging zoonosis. Like malaria agent Plasmodium, the parasite Babesia attacks and damages host's red cells (Dvoraková and Dvorácková, 2007).

In South Africa, two cases were identified as Babesia intraerythrocytic characteristic morphology. One patient recovered following treatment with quinine and tetracycline but, second died despite of the specific treatment (Bush et al, 1990). In Nigeria, Babesia spp. antibodies were detected in normal pop- 
ulation by using immunoflurescence antibody test (IFA). Nigerian strains $B$. bigemina and $B$. bovis in bovine and Babesia ratite in the semi-domestic rat Arvicanthis niloticas were used as antigens, positivity of 94,173 sera, which reacted with at least one of three antigens (Leeflang et al, 1976).

In Egypt, only four human babesiosis cases were reported (El Bahnasawy et al, 2011). The bovine babesiosis was caused mainly by Babesia bovis and B. bigemina. B. bovis parasites were known to be transmitted to the Egyptian animals by Rhipicephalus micropl$u$ s but $B$. bigemina was known to be transmitted by both $R$. microplus and $R$. annulatus (Abdel-Shafy and Mahmoud, 2020; Adham et al, 2009) as well as from rodents and domestic animal.

This study aimed to screen the Egyptian human Babesia carriers by using a known Babesia strain among blood donors in Qena Governorate, Upper Egypt, with respect to all clinical requirements and regulations.

\section{Materials and Methods}

Study area: Qena Governorate is one of the Upper Egyptian Governorates those stretches along Nile Valley. It is an agricultural governorate so that activities of the majority of the inhabitants are farmers and animal husbandry mainly cattle, camel sheep and goats.

Study design: Aseptic sera were randomly collected from 43 Egyptian blood donors attended South Valley University Hospitals from November 2016 to April 2017. All sera were serological examination by indirect fluorescent antibody test (IFA). Positive and negative IFA-cases were evaluated by western blot (WB) analysis, as well as the routine serological examination for the HBV, HCV and HIV (Hu et al, 2019).

Laboratory workup: Specific pathogen free golden hamsters (Std: Syrian) bat 4 weeks old were purchased from SLC Inc. (Shizuoka, Japan). Animal experimentation was carried out after the Laboratory Animal Control Guidelines of National Institute of Infectious Diseases (With permission Nos. 213126 and
114014). Erythrocytes infected with B. microti Hobetsu lineage, IoSG2003 strain, which was isolated from Ixodes ovatus tick in Japan, was used to prepare the antigens for indirect fluorescent antibody test and western blot analysis (Zamoto-Niikura et al, 2015).

Indirect fluorescent antibody test: Antigen slide was prepared (Zamoto-Niikura et al, 2016). The patient's serum was diluted $1: 32$ with Tris buffered saline containing 5\% immunoblock (DS Pharma) and Tween 20. The slides were placed in a humidified chamber and $20 \mu \mathrm{l}$ of the diluted serum was added to each well. After $1 \mathrm{hr}$ of incubation at $37^{\circ} \mathrm{C}$, the slides were washed in PBS \& $20 \mu$ of Alexa Fluor488 conjugated goat anti-human IgG $(\mathrm{H}+\mathrm{L})$ diluted 1:500 (Life Technologies). Then, the slides were incubated at room temperature for $1 \mathrm{hr}$, washed in PBS, and then examined with a fluorescence microscope (Olympus IX71) x200. Hamster antiserum raised against B. microti IoSG2003 was used as control.

Western blot analysis: antigens were separated by $10 \%$ SDS-PAGE. The separated proteins were blotted onto Immobilon-P PVDF membrane (Millipore) that was blocked with $5 \%$ skim milk in Tris buffered saline with $0.1 \%$ Tween 20 . The membranes were incubated with patient's serum (1:50) and then with goat polyclonal antibody to human IgG (alkaline phosphatase, Sigma). The immunoreactive antigens were detected by using 5bromo-4-chloro-3-indolylphosphatenitroblue tetrazolium alkaline phosphatase (NBT/BCI P) liquid substrate system (Sigma). Hamster antiserum raised against the $B$. microti IoSG 2003 was diluted 1:200 as control.

Anti-HCV, HBsAg \& HIV antibody testing were performed by using commercially available assays (Abbott Laboratories, Abbot Park, IL, USA). Data were expressed in numbers and numerically percentage.

\section{Results}

The present study was conducted on 43 participants of whom $20(46.5 \%)$ were males and $23(53.5 \%)$ were females with ages ranged from 17 to 40 years old. A total of 17/ 
$43(39.5 \%)$ patients were suffered from viral hepatitis (11 patients were positive to $\mathrm{HCV}$ antibodies and six were positive to $\mathrm{HbsAg}$ ), but none of them were HIV positive.

Using IFA test, it was found that 13/43 patients were Babesia positive (30.2\%), five of them were females and eight were males. Positive samples were reactive at different titers more than 1:32, which was the recommended positive value. General examination showed that six patients out of 13 positive suffered from viral hepatitis (two HBV $\&$ four $\mathrm{HCV}$ ) but the remaining seven patients were negative for viral hepatitis (Tab. 1; Fig. 1).

By using Western blot analysis to confirm positive results obtained by IFA tests, out of the 13 positive IFAT samples, five patients only were positive, one sample reacted nonspecifically to more than one lineage of $B$. microti and the seven IFAT positive samples were WB negative.

To confirm the IFA negative results, WB analyzed three randomly selected IFA negative samples was performed. Two out of the three samples reacted to more than one lineage of $B$. microti which was considered as non-specific reaction and only one showed weak positive reaction to $B$. microti hobetsu type (Tab. 2; Fig. 2). The combined use of IFA \& WB proved five patients (one female and four males) to be babesiosis positive $(11.6 \%)$, three out of these five positive patients were $\mathrm{HCV}$ antibodies positive.

Table 1: Positive and negative Babesia samples using indirect fluorescent antibody.

\begin{tabular}{|c|c|c|c|c|c|}
\hline IFAT & No. & Percent & \multicolumn{2}{|c|}{ Hbs-Ag positivity } & HCV antibody positivity \\
\hline Negative & 30 & $69.8 \%$ & \multicolumn{2}{|c|}{$4(13.3 \%)$} & $7(23.3 \%)$ \\
\hline Positive & 13 & $30.2 \%$ & \multicolumn{2}{|c|}{$2(15.3 \%)$} & $4(31 \%)$ \\
\hline Total & 43 & $100.0 \%$ & \multicolumn{2}{|c|}{$6(14 \%)$} & $11(25.6 \%)$ \\
\hline \multicolumn{6}{|c|}{ Table 2: Blood donors examined by IFAT and WB analysis } \\
\hline Sex & Age & \multicolumn{2}{|c|}{ Hepatitis markers } & IFAT & WB \\
\hline Male & 35 & \multicolumn{2}{|c|}{ HBV } & \pm & Negative \\
\hline Female & 34 & \multicolumn{2}{|c|}{ HBV } & $\mathrm{x} 64$ & Negative \\
\hline Female & 30 & \multicolumn{2}{|c|}{ None } & $x 64$ & Negative \\
\hline Female & 35 & \multicolumn{2}{|c|}{ None } & $\mathrm{x} 64<$ & Positive (HOBETSU specific) \\
\hline Male & 40 & \multicolumn{2}{|c|}{ None } & $\mathrm{x} 64$ & Positive (HOBETSU specific) \\
\hline Male & 32 & \multicolumn{2}{|c|}{ None } & $\mathrm{x} 64$ & Negative \\
\hline Female & 26 & \multicolumn{2}{|c|}{ None } & $\mathrm{x} 64$ & Negative \\
\hline Male & 40 & \multicolumn{2}{|c|}{ Hepatitis C } & $\mathrm{x} 64$ & Positive (HOBETSU specific weak) \\
\hline Female & 30 & \multicolumn{2}{|c|}{ Hepatitis B } & Negative & Positive (HOBETSU specific weak) \\
\hline Male & 39 & \multicolumn{2}{|c|}{ Hepatitis C } & $\mathrm{x} 64$ & Positive (HOBETSU specific) \\
\hline Female & 25 & \multicolumn{2}{|c|}{ None } & $\mathrm{x} 64$ & Negative \\
\hline Male & 17 & \multicolumn{2}{|c|}{ Hepatitis C } & $\mathrm{x} 64<$ & Positive (HOBETSU specific) \\
\hline Male & 31 & \multicolumn{2}{|c|}{ None } & Negative & Positive (non-specific) \\
\hline Male & 31 & \multicolumn{2}{|c|}{ None } & $\times 32$ & Negative \\
\hline Male & 28 & \multicolumn{2}{|c|}{ Hepatitis B } & Negative & Positive (non-specific) \\
\hline Male & 40 & \multicolumn{2}{|c|}{ Hepatitis C } & $\mathrm{x} 64$ & Positive (HOBETSU specific) \\
\hline
\end{tabular}

\section{Discussion}

Rodents are major reservoir for B. microti group worldwide and various species including species of Apodemus, Myodes, Microtus, Ruttus and Sigmodon were infected (Saleh et al, 2015). In Egypt, B. microti was identified in $R$. rattus, $R$. norvegicus, Acomys c. dimidiatus and Dipodillus $d$. dasyullus by microscopic examination of Giemsa stained erythrocytes (El-Bahrawy et al, 1993). Rodents were frequently occur in the farmland, such as sugar cane, and are supposed to be Arvi- canthis niloticus and $R$. norvegicus (El-Kady et al, 1998; Farghal et al, 2000).

In the present study, three strains within $B$. microti group were used as antigens since human babesiosis in the world was generally caused by $B$. microti US lineage (ZamotoNiikura et al, 2016). Strikingly five patients having antibodies reactive to one of the $B$. microti group, Hobetsu lineage was identified. This result led to confirm by the western blot analysis. The Hobetsu lineage was reported only in Japan where rodents were ma- 
jor reservoir for this lineage throughout the country and human infection was evident by retrospective serological survey where spotted fever (tick-borne) was endemic (Tsuji et $a l, 2001)$. In the western blot analysis, some patients had specific antibodies reactive to approximately $35 \mathrm{kDa}$ Hobetsu lineage antigen, which was also recognized by convalescent serum of hamster.

In Egypt, four proven human babesiosis cases were reported. A splenectomized farmer in El-Minia Governorate who was suffered from fever, myalgia and anorexia, was the first case of human babesiosis. The patient serum showed positive (1:30) against Babesia caballi, though cross-immune reaction against Plasmodium spp. was not denied (Leeflang et al, 1976). The second case of human babesiosis was a farmer from El-Minia Governorate, referred to Ain-Shams University Hospitals with prolonged fever of unknown origin, anemia, hepatomegaly and splenomegaly, and previously underwent corticosteroid therapy and was sero-negative for malaria, but with typical ring forms of Babesia in thin and thick blood smears (Michael et al, 1987). The third case was a 21 years-old young manual worker in car repairing center from Alexandria was referred to the fever hospital as he suffered from three months fever of unknown origin. Before being referred, he was previously diagnosed as a case of an acute rheumatic fever and was kept under corticosteroid therapy for $10 \mathrm{we}$ eks, with fluctuating fever without any response to either cortisone or broad spectrum antibiotic. On admission he was feverish, pulse 115/minute, \& Bp. 110/60, cachetic, anemic and underweight. There was a reddish brown rash over the chest and abdomen which started as a small red macula on then gradually enlarged and occupied the whole chest and creped over the abdomen. A subcutaneous nodule was found over the dorsum of his left hand $(3 \mathrm{~cm}$ in diameter, soft, slightly tender, movable and not attached to the surrounding structures). There was a hepatomegaly $(8 \mathrm{~cm}$ mid-clavicular consistency firm with slight tenderness) and splenomegaly (4 fingers, firm and slightly tender), but without lymph node enlargement. The chest and heart were clinically free except for tachycardia and haemic murmurs all over his chest. He was proved to be babesiosis case by positive thin and thick blood films. The patient was given Quinine as $650 \mathrm{mg} / 8 \mathrm{~h} \mathrm{\&}$ Clindamycinas $600 \mathrm{mg} / 8 \mathrm{~h}$ ), also blood exchange improved the fever (El Bahnasawy and Morsy, 2008). The last proven human was a 12 years old boy was referred to the hospital with intermittent fever of unknown origin. On clinical, parasitological and serological bases the case proved to be babesiosis. The boy acquired the infection from his pet dog which was heavily infested with Rhipicephalus sanguineus and suffered a mild feature of animal babesiosis. The boy was successfully treated with Atovaquone plus Azithromycin without relapse for one month follow up. The pet dog was sent to Abbassia Governmental Veterinary Hospital to treat babesiosis and tick infestation (El Bahnasawy et al, 2011). Apart from patients, Adham et al. (2009) in Giza Governorate by PCR studied the prevalence of $B$. bovis and B. bigemina in 5,243 hard and soft ticks. Primers DNA verified from the sequence of Mexico strain of both species were used that generated two fragments of $275 \& 175 \mathrm{bp}$ of $B$. bovis \& $B$. bigemina respectively. Moreover, $B$. behnkei sp. nov, was found in Wagner's gerbil Dipodillus dasyurus from Sinai Mountains. Phylogenetically this novel species is included in the Duncani group, which included the emerging zoonotic parasites, $B$. duncani and Babesia sp. CA1 (Arai et al, 2003). Antigenantibody cross reactivity between $B$. microti group and $B$. duncani was supposed to be low (Bajer et al, 2014).

Several studies reported various Babesia spp. in farm animals such as cattle and sheep in Qena Governorate. Fereig et al. (2017) reported that the seroprevalence of babesiosis in cattle was $9.0 \%$ \& $33.2 \%$ for B. bovis and $B$. bigemina respectively. Moreover, Babesia bigemina and $B$. bovis in ruminants, incl- 
uded cattle, sheep and water buffaloes, calves as well as horses and pets were reported all over Egypt with various infection rates (Nagaty, 1947; Maronpot and Guindy, 1970; Michael and El Refaii, 1982; Mazyad and Khalaf, 2002; Farah et al, 2003; Saleh, 2009: Nayel et al, 2012; Ibrahim et al, 2013; Mahmmod, 2014; Elsify et al, 2015; Mahmoud et al, 2015; Sa-lem et al, 2016; Hussein et al, 2017).

In the current study showed also the association between positivity for $\mathrm{HCV}$ antibodies and Babesia antibodies. Al-Agroudi et al. (2029) in retrospective study evaluated the malaria situation in the last 3 years in an Egyptian Fever Hospital. They reported a total of 100 malaria patients were youth returning back from Africa with mainly $P$. $f a$ lciparum followed by $P$. vivax, mixed infection and only one case of $P$. ovale All patients were successfully treated except two whom was co-infected with HIV. This raised a question about association between babesiosis and/or malignant malaria and viral infection?

\section{Conclusion}

No doubt, nowadays, zoonotic diseases in spite of the causative agent top the medical health problems worldwide. Human babesiosis shared signs and symptoms with many arthropod-borne infectious diseases, especially malignant malaria, even in stained blood smears. No doubt, blood smears for Babesia species needs a well-trained technologist. This may pave the way to misdiagnosis and thus its underestimation not only in Egypt but also in other regional countries.

Screening of blood donors for human babesiosis is a must to exclude babesiosis. IFA test proved a preliminary test for screening but must be confirmed by highly specific and more accurate WB analysis.

Ethical statement: The study was approved by the Institutional Ethics Review Board of South Valley University, approval No. 59. Informed consent was obtained from each participant and all were dealt with the humanity rules.
Conflict of interest: The authors declared that they neither have conflict of interest nor received fund

\section{Acknowledgements}

The authors would like to thank Dr. Aya Zamoto-Niikura, Division of Experimental Animal Research, National Institute of Infectious Diseases, 4-7-1 Gakuen, Musashimurayama, Tokyo 208-0011, Japan, for her kind help and providing materials.

\section{References}

Abdel-Motagaly, AME, Ibrahim, AMA, Mor sy, TA, 2017: An intervention program on blood protozoa acquired by needle stick injury and infection control. J. Egypt. Soc. Parasitol. 47, 2: 309-22

Abdel-Shafy, S, Mahmoud, MS, 2002: Morphological and ultrastructural studies on Babesia bigemina local strain in haemolymph and salivary glands of infected Boophilus annulatus females. J Egypt Vet Med Assoc. 62, 6:247-56 Adham, FK, Abdel-Samie, EM, Gabre, RM, el-Hussein, H, 2009: Detection of tick blood parasites in Egypt using PCR assay I-Babesia bovis and Babesia bigemina. Parasitol. Res. 105, 3:721-30.

Al-Agroudi, MA, Ahmad, GMS, Kondo, MK, Morsy, TA, 2018: Malaria situation in Egypt, the last three years: Retrospective study in an Egyptian Fever Hospital. J. Egypt. Soc. Parasitol. 48, 3:635-44.

Arai, S, Tsuji, M, Kaiho, I, Murayama, H, Zamoto, A, et al, 2003: Retrospective seroepidemiological survey for human babesiosis in an area in Japan where a tick-borne disease is endemic. J. Vet. Med. Sci. 65:335-40.

Bajer, A, Alsarraf, M, Bednarska, M, Mohallal, EM, Mierzejewska, EJ, 2014: Babesia behnkei sp. nov., a novel Babesia species infecting isolated populations of Wagner's gerbil, Dipodillus dasyurus, from the Sinai Mountains, Egypt. Parasit. Vectors 7:572-9.

Bush, JB, Isaacson, M, Mohamed, AS, Pogieter, FT, de Waal, DT, 1990: Human babesiosis: A preliminary report of 2 suspected cases in South Africa. S. Afr. Med. J. 78:699-73.

Dvoraková, HM, Dvorácková, M, 2007: Babesiosis, a little known zoonosis. Epidemiol. Mikrobiol. Imunol. 56, 4:176-80.

El Bahnasawy, MM, Khalil, HH, Morsy TA, 
2011: Babesiosis in an Egyptian boy acquired from pet dog, and a general review. J. Egypt.

Soc. Parasitol, 41, 1:99-108.

El Bahnasawy, MM, Morsy, TA, 2008: Egyptian human babesiosis and general review. J. Egypt. Soc, Parasitol 38:265-72.

El-Bahrawy, AF, Nafei, SM, Morsy, TA, Farr ag, AMK, 1993: Natural Babesia infection sought in black and. Norway rats. J. Egypt. Soc. Parasitol. 23, 2:349-55.

El-Kady, GA, Makled, KM, Morsy, TA, Morsy, ZS, 1998: Rodents, their seasonal activity, ecto- and blood-parasites in Saint Catherine area, South Sinai Governorate, Egypt. J. Egypt Soc. Parasitol. 28, 3:815-26.

Elsify, A, Sivakumar, T, Nayel, M, Salama, A, Elkhtam, A, et al, 2014: An epidemiological survey of bovine Babesia and Theileria parasites in cattle, buffaloes, and sheep in Egypt. Parasitol. Int. 64, 1:79-85.

Farah, AW, Hegazy, NA, Romany, M, Soliman, YA, Daoud, AM, 2003: Molecular detection of Babesia equi in infected and carrier horses by polymerase chain reaction. Egypt. J. Immunol. 10, 2:73-9.

Farghal, AI, El Eraky, SA, Abdel Gawad, KH, AA Abazaid, AA, 2000: Laboratory and field evaluation of some rodenticides against rodent species in Upper Egypt. The $2^{\text {nd }}$ Sci. Conf. Agric. Sci. Assiut 531-536

Fereig, RM, Mohamed, SGA, Mahmoud, HY A, AbouLaila, MR, Guswanto, A, et al, 2017: Seroprevalence of Babesia bovis, B. bigemina,

Trypanosoma evansi, and Anaplasma marginale antibodies in cattle in southern Egypt. Ticks Tick-Bor. Dis. 8:125-31.

Homer, MJ, Aguilar-Delfin, S, Telford $3^{\text {rd }}, \mathrm{S}$ R, Krause, PJ, Persing, DH, 2000: Babesiosis review. Clin. Microbiol. Rev. 133:451-69.

Hu, J, Liu, K, Luo, J, 2019: HIV-HBV \& HIV-HCV coinfection and liver cancer development. Cancer Treat Res. 177:231-250.

Hussein, NM, Mohammed, ES, Hassan, AA, El-Dakhly, KM, 2017: Distribution pattern of Babesia and Theileria species in sheep in Qena Governorate, Upper Egypt. Arch. Parasitol. 1: 102-5.

Ibrahim, HM, Adjou Moumouni, PF, Mohammed-Geba, K, Sheir, SK, Hashem, IS, et al, 2013: Molecular and serological prevalence of Babesia bigemina and Babesia bovis in cattle and water buffalos under small-scale dairy farming in Beheira and Faiyum Provinces, Egypt.
Vet. Parasitol. 198, 1/2:187-92.

Leeflang, P, Oomen, JM, Zwart, D, Meuwissen, JH, 1976: The prevalence of Babesia antibodies in Nigerians. Int J Parasitol 6: 159-61.

Mahmmod, Y, 2014: Natural Babesia bovis infection in water buffaloes (Bubalus bubalis) and crossbred cattle under field conditions in Egypt: A preliminary study. J Arthropod-Borne Dis. 8, 1:1-9.

Mahmoud, MS, Kandil, OM, Nasr, SM, Hendawy, SH, Habeeb, SM, et al, 2015: Serological and molecular diagnostic surveys combined with examining hematological profiles suggests increased levels of infection and hematological response of cattle to babesiosis infections compared to native buffaloes in Egypt. Parasit. Vectors 8:319-21

Maronpot, RR, Guindy, E. 1970: Preliminary study of Babesia gibsoni Patton in wild carnivores and domesticated dogs in Egypt. Am. J. Vet. Res. 31, 4:797-9.

Mazyad, SA, Khalaf, SA, 2002: Studies on Theileria and Babesia infecting live and slaughtered animals in Al Arish and El Hasanah, North Sinai Governorate, Egypt. J. Egypt. Soc. Parasit ol. 32, 2:601-10.

Michael, SA, El Refaii, AH, 1982: The effect of imidocarb dipropionate on Babesia ovis infection in sheep. Trop. Anim. Hlth. Prod. 14, 1:1-2. Michael, SA, Morsy, TA, Montasser, MF, 1987: A case of human babesiosis (Preliminary case report in Egypt). J. Egypt. Soc. Parasitol. 17, 2:409-10

Nagaty, HF, 1947: Some new and rare records of piroplasmosis with a list of the species of Babesia and Theileria so far recorded from Egypt. Vet. Rec. 59, 11:145-7.

Nayel, M, El-Dakhly, KM, Aboulaila, M, Elsify, A, Hassan, H, et al, 2012: The use of different diagnostic tools for Babesia and Theileria parasites in cattle in Menofia, Egypt. Parasitol. Res. 111, 3:1019-24.

Onyiche, TE, Suganuma, K, Igarashi, I, Yokoyama, N, Xuan, X, et al, 2019: A review on equine piroplasmosis: Epidemiology, vector ecology, risk factors, host immunity, diagnosis and control. Int. J. Environ. Res. Publ. Hlth. 16, 10: 17-36

Ord, RL, Lobo, CA, 2015: Human Babesiosis: Pathogens, prevalence, diagnosis and treatment. Curr. Clin. Microbiol. Rep. 2, 4:173-81.

Saleh, AM, Adam, SM, Abdel-Motagaly, AM E, Ibrahim, AMA, Morsy, TA, 2015: Human 
babesiosis: A general review with special reference to Egypt. J. Egypt. Soc. Parasitol. 45, 3:493510.

Saleh, AMA, El Nakib, MM, Malek, DMA, Morsy, TA, 2019: Mini- review on malaria and human immunodeficiency virus in Sub-Sahara Africa. J. Egypt. Soc. Parasitol. 49, 1:61-72

Saleh, MA, 2009: Erythrocytic oxidative damage in crossbred cattle naturally infected with Babesia bigemina. Res. Vet. Sci. 86, 1:43-8.

Salem, NY, Yehia, SG, Farag, HS, Elkhiat, M A, 2016: Clinical, hemato-biochemical alterations and oxidant-antioxidant biomarkers in Babesia-infected calves. Int. J. Vet. Sci Med. 4, 1:1722

Tsuji, M, Wei, Q, Zamoto, A, Morita, C, Arai, S, et al, 2001: Human babesiosis in Japan: Epizootiologic survey on rodent reservoir and isola- tion of new type of Babesia microti-like parasite.

J. Clin. Microbiol. 39:4316-22.

Yabsley, MJ, Shock, BC, 2012: Natural history of zoonotic Babesia: Role of wildlife reservoirs. Int. J. Parasitol. Parasit. Wildl. 2:18-31.

Zamoto-Niikura, A, Masayoshi, T, Rui, M, Haruyuki, H, Chiaki, I, et al, 2015: Survey and Molecular Analysis of Babesia microti Group Parasites in Japan. In book: Epidemiology Theory, Research and Practice, Edition: $1^{\text {st }}$, Publisher: iConcept Press Ltd., Editors: iConcept Press Ltd

Zamoto-Niikura, A, Morikawa, S, Hanaki, KI, Holman, PJ, Ishihara, C, 2016: Ixodes persulcatus ticks as vectors for the Babesia microti U.S. Lineage in Japan. Appl. Environ. Microbiol. 82, 22: 6624-32.

\section{Explanation of figures}

Fig. 1: B. IFA test of Egyptian patients' sera for anti-IgG against B. microti hobestsu lineage. A: Infected hamster positive control.

Fig. 2: Protein pattern analysis by western blot technique for sera of $B$. microti hobetsu type infected patients \& infected control hamsters.
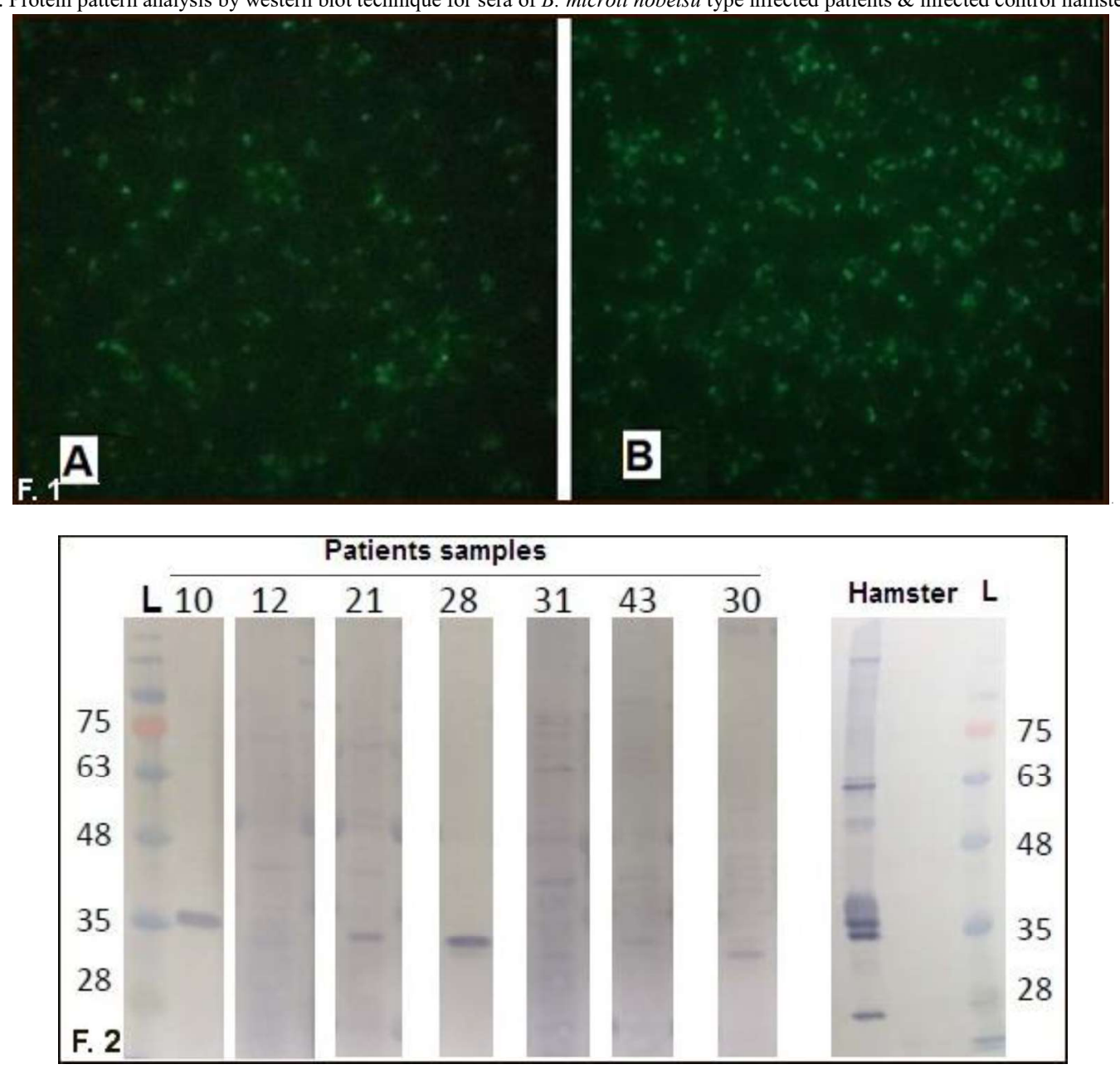